\title{
A Versatile New Tactic for Fruit Tree Micrografting
}

\author{
Ahmed A. Obeidy and \\ M.A.L. Smith
}

Additional index words. apple, cherry, citrus

Summary. Micrografting is au effective technique for elimination of viruses, early diagnosis of grafting incompatibilities, rejuvenation of mature tissue, and bypassing the juvenile phase in fruit trees. Current micrografting procedures are difficult, impractical, expensive, and generally result in an inefficient rate of successful graft production. To alleviate some of these limitations, a unique apparatus was designed to splice the in vitro-derived scion and rootstock together during the micrografting process. The dual-layer device was constructed with an outer layer of aluminum foil, with flexibility to facilitate manipulation during the grafting of micro-scale plants. A delicate, absorbent inner layer of paper toweling cushions the plant tissue. It also may be treated with hormones and other compounds. After healing, it is easy to remove the grafting apparatus from the grafted plant without damaging the tissues. This apparatus may be used to unite a scion and a rootstock with different stem diameters. Shoot-tip cultures of 'McIntosh' and M.7 apple and 'North Star' sour cherry, and in vitro seedlings of lemon, orange, and grapefruit were used as a source of in vitro scions and rootstocks. Successful graft unions were developed, and the grafted plants were transplanted into the greenhouse environment.

icrografting is a technique that potentially can combine the advantages of rapid in vitro multiplication with the increased productivity that results from grafting superior rootstock and scion combinations (Gebhardt and Goldbach, 1988).

Department of Horticulture, University of Illinois, 1201 S. Dorner Dr., Urbana, IL 61801. 
Virus elimination may be accomplished by meristem tip culture of woody species, followed by micrografting (Boxus and Druart, 1986; Jonard, 1986). The unproductive juvenile phase of citrus can be circumvented by micrografting to a rootstock that induces early maturity (Murashige et al., 1972). Micrografting also provides an alternative production technique when microshoots are difficult to root (Preece et al., 1989). Micrografting has applications for physiological analysis of the rejuvenation of mature-phase plants (Jonard, 1986), facilitates the early diagnosis of grafting incompatibilities, and may provide a model for in-depth analysis of the incompatibility phenomenon (Chimot-Schall et al., 1986; Jonard, 1986; Jonard et al., 1990). Micrografting has particular utility in fruit tree production (Jonard, 1986).

The challenge of successfully grafting the very small and delicate material from in vitro plants has warranted development of novel techniques to facilitate the process. In micrografting experiments with citrus, Murashige et al. (1972) devised special micro-scalpels from razor blades to accomplish an excision and transfer the shoot apex to the decapitated rootstock. Navarro et al. (1975) isolated a shoot tip composed of the apical meristem and subjacent tissue from the desired source using a razor blade sliver attached to a surgical handle as a scalpel. The scion was transferred to the top cut surface of the decapitated epicotyl, or alternatively, it was inserted in an inverted-T incision.

In particular, variables associated with the proper attachment of stock and scion, protection of the union during healing, and the removal of grafting implements after healing have had a significant influence on the success of the procedure. In vitro graft unions of apple have been connected using a filter paper bridge to hold stock and scion together and facilitate callus formation (Huang and Millikan, 1980). Jonard et al. (1983) applied an elastic strip to protect the grafted zone for peach microcultures. For Prunus microcuttings, Gebhardt and Goldbach (1988) used translucent silicon tubing to provide support and maintain contact between the scion and rootstock. The success of these micrografts depended in part on the ability to remove the support without damaging the graft unions.
Micrografting tends to be an expensive, time-consuming production step, due to the technical expertise required to prepare successful grafts on small-scale material and the handling difficulties associated with preserving the delicate graft union. At present, the failure rate for micrografts is higher than desired; it is estimated that development of a superior technique would represent a significant advancement, particularly for virus elimination work (T. Williams, National Clonal Germplasm Repository for Citrus/Date, personal communication). Due to the multiple uses for and advantages of micrografting, this technology may be ofinterest or potential practical value to technicians, researchers, nursery operators, and teachers. As such, it can provide valuable information for extension specialists and agents, consultants, or others who serve that audience. Professionals in each of these arenas would benefit from the introduction of a simpler, more-efficient micrografting procedure that is less dependent on mastery of complex techniques.

This report describes a simplified micrografting technique using a novel apparatus to aid in splicing the scion and rootstock. The improved procedure features several advantages in manipulation and maintenance of grafted plants that will contribute to the practical utility of micrografting as a tool in fruit tree biotechnology.

Micrografting apparatus. A double-layer apparatus was constructed with a sheet of aluminum foil (outer layer) and absorbent paper toweling (inner layer) to facilitate splicing the scion and the rootstock during the micrografting process. The outer and inner layers were fused with a thin layer of rubber cement, and cut to $1.3 \times 3.9$ cm rectangles (Fig. 1A). A smaller $1.0 \times$ $1.3-\mathrm{cm}$ rectangular piece was excised at one end of the main rectangle to create the first arm of the apparatus. On the opposite end, a 1.3-cm horizontal cut was made to create the other arm (Fig. 1B). The completed micrografting apparatus, a cylinder with two free arms, was formed by curling the body around a rectangular rod, $4 \mathrm{~mm}^{2}$ in cross section (Fig. 1C). The micrografting devices were collected in petri dishes and autoclaved at $121 \mathrm{Cat} 14 \mathrm{~kg} \cdot \mathrm{cm}^{-2}$ for $20 \mathrm{~min}$ before aseptic use (Fig. 2). For some of the micrografting trials, the inner layer of toweling was treated with a solution of 6-benzylaminopurine (BAP) supply- ing $0.025 \mathrm{mg}$ per apparatus before autoclaving.

Plant material. In vitro shoots from aseptic shoot-tip cultures of 'McIntosh' and M.7 apple ( Malus domestica Borkh.) and 'North Star' sour cherry (Prunes cerasus L.) and seedlings of lemon ( Citrus limon L. Burm. f.), orange ( Citrus sinensis L. Osbeck), and grapefruit ( Citrus paradisi Macf.) grown in vitro were used as the source of in vitro micrograft scions and rootstocks. The surfaces of citrus fruits were washed with a mild detergent solution and rinsed with sterile, deionized water; fruits were then opened under a laminar flow hood using a sterile blade. Seeds were removed aseptically and cultured on agarsolidified medium with no other nutrients. Apple and cherry cultures were on a modified MS medium (Murashige and Skoog, 1962) supplementedwith $30 \mathrm{~g} \cdot$ liter $^{-1}$ sucrose, $2 \mathrm{mg} \cdot$ liter $^{-1}$ glycine, $50 \mathrm{mg} \cdot$ liter $^{-1}$ ascorbic acid, a vitamin mixture (Staba, 1962), $9 \mu \mathrm{M} \mathrm{BAP,} \mathrm{and}$ $0.5 \mu \mathrm{M} a$-naphthaleneacetic acid (NAA). After 4 to 6 weeks on the MS medium, shoots were collected for use in grafting experiments. Citrus seedlings were used 4 to 6 weeks after germination. Single apple shoots to be used as rootstocks were rooted in vitro after transfer to medium supplemented with $7.5 \mu \mathrm{M}$ indole-3-butyric acid (IBA).

Micrografting procedure. Aseptic conditions were maintained throughout all stages of the micrografting process. All steps were performed under a laminar flow hood, and sterile latex laboratory gloves were used during handling of plant material and grafting supplies. Seedlings of lemon, orange, and grapefruit were removed carefully from the agar medium with sterile forceps. For use as citrus rootstocks, seedlings were cut back to $1 \mathrm{~cm}$ above the cotyledonary nodes, and leaves were excised using a microscalpel. Terminal shoots to be used as citrus scions were excised from other seedlings at $\approx 2 \mathrm{~cm}$ below the apex. Lower leaves were removed from the basal $1 \mathrm{~cm}$ of scions. For apple rootstocks, rooted in vitro plantlets of 'McIntosh' and M.7 apple were cut back to $\approx 2 \mathrm{~cm}$ above the root zone. Terminal 2-cm shoots of proliferating 'McIntosh' shoots were excised as scions. For 'North Star' sour cherry, in vitro microcuttings were used as both scions and rootstocks. Excised scions 


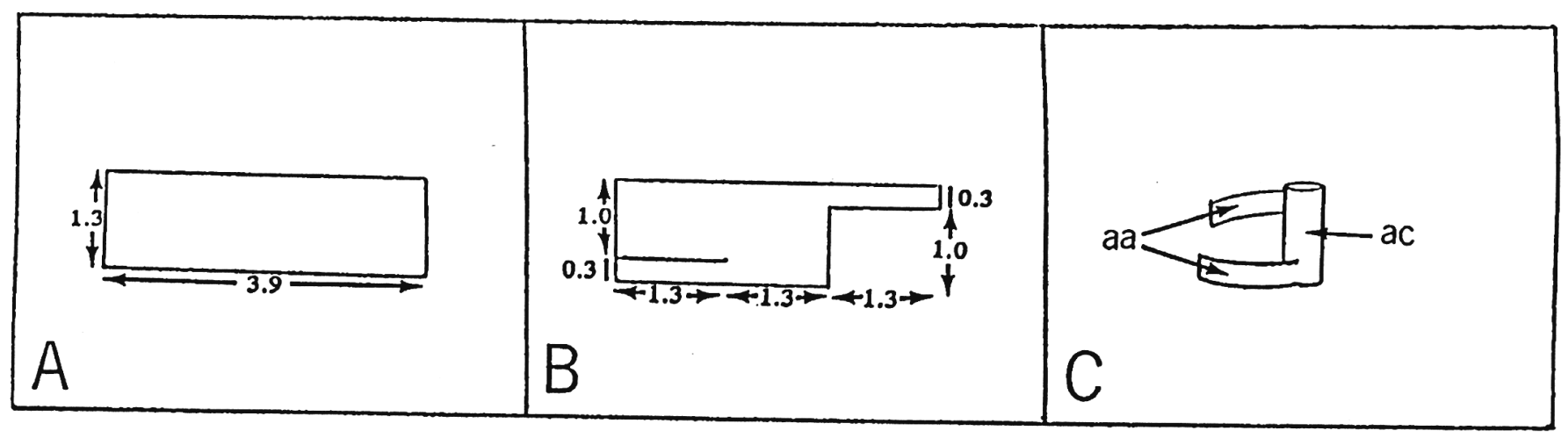

Fig. 1. Diagram of micrografting apparatus construction and assembly. aa = apparatus free arms, ac = apparatus cylinder. Measurements gipen in centimeters. A $1.3 \times 3.9$-cm double-layer rectangle. B Creating tbe apparatus arms by excising a $1.0 \times 1.3$-cm rectangular section at one corner of tbe main rectangle and making a borisontal cut on tbe opposite side of tbe main rectangle. C Tbe micrografting apparatus, a cylinder witb two free arms, was formed by curling tbe body on a rectangular rod witb a 4-mm ${ }^{2}$ cross-sectional area.

and rootstocks were stored in sterile, deionized water until used in the grafting process.

To prepare each graft, the cut end of the rootstock was inserted into one end of the sterile apparatus cylinder to about the midpoint, then the lower free arm of the apparatus was twisted around the rootstock. The cut end of the scion was inserted into the other end of the apparatus cylinder to meet

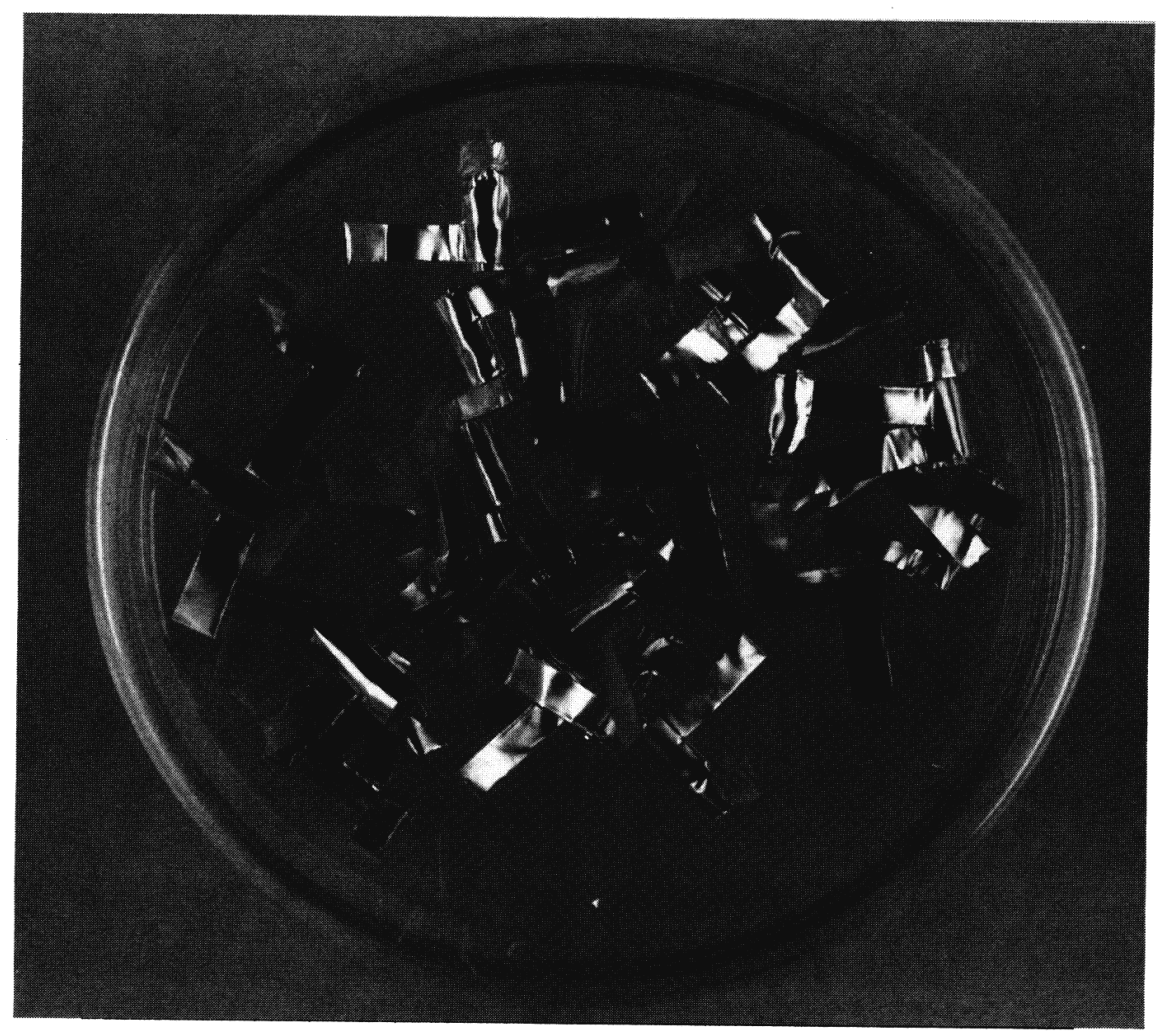

Fig. 2. Tbe micrografting devices, autoclaved in petri disbes and ready to use in the micrografting process. The sterile devices were later fastened using sterile glopes to ensucre aseptic conditions tbroughout the micragrafting process. the cut end of the rootstock. The upper free arm of the apparatus was twisted around the scion, binding and fixing it to the rootstock inside the apparatus cylinder (Fig. 3 A and B). The time required to prepare. grafts was $\approx 15$ sec per sample.

Micrografted apple and cherry plants were next inserted vertically to the depth of the rootstock crown into culture tubes containing the same agar-

solidified medium used to grow the shoot cultures. Citrus micrografts were cultured in a hormone-free agar-solidified medium, or, alternatively, in GA7 vessels (Magenta Corp., Chicago) containing $150 \mathrm{ml}$ of sterile, fine vermiculite supplemented with $100 \mathrm{ml}$ of liquid medium (without sucrose). At least 20 grafts for each scion-rootstock combination were examined in each treatment. Additional experiments with 20 replicates/treatment were prepared to test the effects of BAP pretreatment of the apparatus for callus promotion for apple and cherry scion-rootstock combinations.

At weekly intervals after 3 weeks, the graft union was inspected to determine the onset of callus formation and the progress of healing. After a maximum of 8 to 10 weeks, the apparatus was removed from grafted plants (Fig. 3C). At this point, plants were removed from aseptic in vitro conditions and conditioned gradually to the ex vitro environment. Plants were transplanted into a moist, sterile 1 soil : 1 peat : 1 perlite mixture contained in clean, surface-sterilized 15-cm (1000$\mathrm{c}^{3}$ ) plastic pots, and placed under high humidity in a growth chamber. Humidity was gradually decreased over a 4-week period to acclimatize the plants, after which they were transferred to a greenhouse bench for continued growth.

Healing was achieved within 3 to 8 weeks after using the apparatus 'to splice scions and rootstocks. Success rates for individual scion-rootstock combinations are given in Table 1. Stable graft unions were developed using either agar medium or vermiculite to hold the plants during the healing 
TECHNOLOGY AND PRODUCT REPORTS

Table 1. Success rates for individual scionrootstock combinations, with no cytokinin pretreatment of the micrografting apparatius. All micrografts were beld in agar-solidified medium during graft union formation.

\begin{tabular}{|c|c|}
\hline $\begin{array}{l}\text { Scion-rootstock } \\
\text { combination }\end{array}$ & $\begin{array}{c}\text { Successful graft } \\
\text { unions (\%) }\end{array}$ \\
\hline \multicolumn{2}{|l|}{ Apple } \\
\hline McIntosh-McIntosh & 30 \\
\hline McIntosh-M.7 & 25 \\
\hline \multicolumn{2}{|c|}{ Sour cherry } \\
\hline North Start-North Star & 20 \\
\hline \multicolumn{2}{|l|}{ Citrus } \\
\hline Lemon-lemon & 50 \\
\hline Lemon-grapefruit & 35 \\
\hline Lemon-orange & 35 \\
\hline Grapefruit-lemon & 35 \\
\hline Orange-lemon & 30 \\
\hline
\end{tabular}

period, with no significant difference in rate of success. BAP treatment of the apparatus promoted faster callus formation for grafted apples and cherry. For example, callus formation was accelerated by $\approx 2$ weeks for 'McIntosh'/ 'McIntosh' homografts and 'McIntosh'/M.7 heterografts, and the percentage of successful grafts was increased from $30 \%$ to $45 \%$ and $25 \%$ to
$45 \%$, respectively, following pretreatment of the apparatus with BAP. Similarly, micrografted cherries also exhibited faster callus formation with BAP treatment, and a $10 \%$ increase in successful graft union formation. Citrus micrografts were not treated with BAP in these experiments; however, Jonard (1987) has reported that cytokinin treatment can enhance grafting success significantly for these species as well. Botrytis contamination observed around some graft unions of the initial citrus micrografts during acclimatization was eliminated with periodic drenches with Daconil at one-half concentration ( $\approx 0.04$ ounces/gal.). The grafted plants were transplanted successfully and acclimatized to the greenhouse environment with nearly $100 \%$ efficiency. All grafted, acclimatized plants produced new growth in the greenhouse. Citrus homografts produced significantly more early scion growth than heterografts. Samples of the grafted plants have been sectioned to determine the anatomical characteristics of the graft union.

The grafting apparatus and simplified procedure described represents a promising alternative method for manipulation of fruit trees in vitro.
The device is comprised of inexpensive, readily available materials, is simple to assemble, and requires minimal time to splice grafts with good rootstock-scion contact. In particular, when scion and rootstock are of different diameters, the cut ends may be angled to maximize cambial contact. Gebhardt and Goldbach (1988) used translucent silicon tubing to connect scion and rootstock during micrografting. However, the connection tends to pinch the delicate plant tissues of both scion and rootstock during attachment and graft union formation (especially when unequal-diameter plant parts are used), and is more difficult to remove after healing, which creates a hazard to the success of the grafts. As described by Navarro and Juarez (1977), the manual dexterity of the operator is one of the most important factors in determining the degree of success in micrografting. For the procedure described here, the apparatus can be removed easily and gently by unwinding the arms of the apparatus to release the plant material.

Previous reports have confirmed the value of cytokinin compounds and antioxidants, applied as drops in liquid


Fig. 3. Tbe micrografting procedure. $S=$ scion, $R=$ rootstock, $G A=$ grafting apparatus, $G U=$ graft union. A Scion, a micrografting device, and a rootstock. The cut end of the rootstock is inserted first into the apparatus cylinder and fixed by twisting the lower free arm around to secure the tissue witbin the cylinder. Tbe cut end of the scion is inserted into the opposite end of the cylinder, and fixed by twisting the upper free arm around. BA completed graft after twisting tbe apparatus arms around a rootstock and a scion. C Grafted plant after bealing and removing tbe graftingapparatius. 
form or in agar blocks, to facilitate healing at micrograft zones (Jonard et al., 1990). Insertion of an agar block containing the antioxidant compound DIECA between the cut scion androotstock of the graft union resulted in superior grafting efficiency for various fruit tree species (Jonard et al., 1983). Similarly, BAP and other phytohormones have facilitated graft union formation in citrus (Jonard et al., 1987). Endriss and Burger (1984) reported substantial increases in successful graft formation by use of cytokinin treatments. Chemicals such as those cited are applied to the grafting zone to alleviate oxidation and enhance callus formation at the cut surface of scion and rootstock. For this work, the absorbent inner layer of the grafting device was treated with BAP to bathe the union continuously during healing and promote callus formation.

The method described is particularly advantageous since all steps up until acclimatization were accomplished under aseptic conditions, eliminating contamination problems that typically plague the micrografting operation. This technique is suitable for year-round micrografting work on in vitro material, and offers an excellent means for reproducing virus-free clones. When virus is difficult to eliminate from some material, the apparatus is also stable for use with combined heat therapy.

\section{Literature Cited}

Boxus B. and P. Druart. 1986. Virus-free trees through tissue culture, p. 24-30. In: Y.P.S. Bajaj (cd.). Biotechnology in agriculture and forestry. vol. 1. Trees I. SpringerVerlag, Berlin.

Chimot-Schall, F., P. Villemur, and R. Jonard. 1986. Essays of rectification of a precocious diagnostic of incompatibilities for the grafting with three techniques in vitro: The micro grafting, the associations of inter nodes and the fusions of callus. Compte Bend. Acad. Sci. Paris, t. 303, Serie III:591-594.

Endriss, M.H. and D.W. Burger: 1984. Micrografting shoot-tip culture of citrus on three trifoliate rootstocks. Scentia Hort. 23:255-259.

Gebhardt, K. and H. Goldbach. 1988. Establishment, graft union characteristics and growth of Prunus micrografts. Physiol. Plant. 72:153-159.
Huang, S. and D.F. Millikan. 1980. In vitro micrografting of apple shoot tips. HortScience 15:741-743.

Jonard, R. 1986. Micrografting and its applications to tree improvement, p. 3148. In: Y.P.S. Bajaj (ed.). Biotechnology in agriculture and forestry. vol. 1. Trees I. Springer-Verlag, Berlin.

Jonard, R., I. Soedharma, and P. Villemur. 1987. The effect of different factors on the improvement of successes of in vitro micrografting in Citrus species. Compte Rend. Acad. Sci. Paris, t. 305, Serie 111:4549.

Jonard, R., J. Hugard, J. Macheix, J Martinez, L. Mosella-Chancel, J.L. Poessel and P. Villemur. 1983. In vitro micrografting and its applications to fruit science. Scientia Hort. 20:147-159.

Jonard, R., D. Lukman, F. Schall, and P. Villemur. 1990. Early testing of graft incompatibilities in apricot and lemon trees using in vitro techniques. Scientia Hort. 43:117-128.

Murashige, T. and F. Skoog. 1962. A revised medium for rapid growth and bioassays with tobacco tissue culture. Physiol. Plant. 15:473-497.

Murashige, T, W.P. Bitters, T.S. Rangan, E.M. Nauer, C.N. Roistacher, and P.B. Holliday. 1972. A technique of shoot apex grafting and its utilization towards recovering virus-free citrus clones. HortScience 7:118-119.

Navarro, L., C.N. Roistacher, and T. Murashige. 1975. Improvement of shoottip grafting in vitro for virus-free citrus. J. Amer. Soc. Hort. Sci. 100:471-479.

Navarro, L. and J. Juarez. 1977. Tissue culture techniques used in Spain to recover virus-free citrus plants. Acta Hort. 78:425435.

Preece, J.E., J.W. Van Sambeek, C.A. Huetteman, and G.R. Gaffney. 1989. In vitro studies with walnut (Juglans) species. The continuing quest for quality black walnut. Proc. 4th Black Walnut Symp., 30 July-2 Aug. 1989.

Staba, E.J 1962. Production of carbiac glycosides by plant tissue culture: 1 . Nutritional requirements in tissue cultures of Digitalis lanata and Digitalis purpurea. J. Pharmacol. Sci. 51:249-254.

\section{Acknowledgements}

We thank Tim Williams, Curator, National Clonal Germplasm Repository for Citrus/Date, Riverside, Calif., for generously supplying plant material. 